\title{
Pulsed EPR investigations of systems modeling molybdenum enzymes: Hyperfine and quadrupole parameters of $0 \times{ }^{-17} \mathrm{O}$ in $\left[\mathrm{Moo}^{17} \mathrm{O}(\mathrm{SPh})_{4}\right]^{-}$
}

\author{
Andrei V. Astashkin, Frank Neese, Arnold M. Raitsimring, J. Jon A. Cooney, Eric \\ Bultman, John H. Enemark
}

\section{Supporting Information}

Figure S1 - Solid traces A and C, cosine Fourier transforms of the primary ESEEM of $\left[\mathrm{Mo}^{17} \mathrm{O}(\mathrm{SPh})_{4}\right]^{-}$obtained at EPR positions A and C, respectively (see Figure 1). Dashed traces $\mathrm{A}$ and $\mathrm{C}$ show the corresponding spectra for $\left[\mathrm{Mo}^{16} \mathrm{O}(\mathrm{SPh})_{4}\right]^{-}$. Experimental conditions: mw frequency, $29.372 \mathrm{GHz}$; mw pulses, $2 \times 17 \mathrm{~ns}$; dead time, $\tau_{\mathrm{d}}=120 \mathrm{~ns}$. The fundamental line of distant protons is labeled " $v_{\mathrm{H}}$ ".

Table S1 - Geometry optimized coordinates of $\left[\mathrm{MoO}(\mathrm{SPh})_{4}\right]^{-}$. 


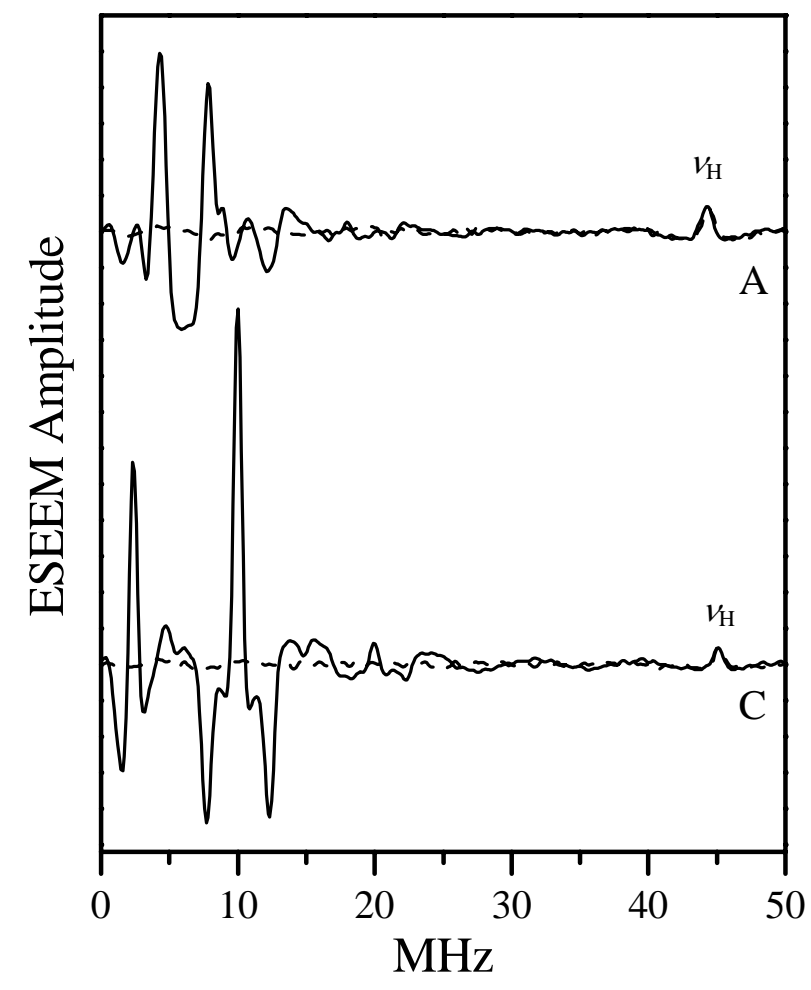

Figure S1 - Solid traces A and C, cosine Fourier transforms of the primary ESEEM of $\left[\mathrm{Mo}^{17} \mathrm{O}(\mathrm{SPh})_{4}\right]^{-}$obtained at EPR positions A and C, respectively (see Figure 1). Dashed traces $\mathrm{A}$ and $\mathrm{C}$ show the corresponding spectra for $\left[\mathrm{Mo}^{16} \mathrm{O}(\mathrm{SPh})_{4}\right]^{-}$. Experimental conditions: mw frequency, $29.372 \mathrm{GHz}$; mw pulses, $2 \times 17 \mathrm{~ns}$; dead time, $\tau_{\mathrm{d}}=120 \mathrm{~ns}$. The fundamental line of distant protons is labeled " $v_{\mathrm{H}}$ ". 
Table S1 - Geometry optimized coordinates of $\left[\mathrm{MoO}(\mathrm{SPh})_{4}\right]^{-}$.

\begin{tabular}{|c|c|c|c|c|c|c|c|}
\hline Mo & 7.151563 & 12.58487 & 8.942549 & $\mathrm{~S}$ & 5.924013 & 10.87506 & 7.727172 \\
\hline C & 5.094466 & 11.50572 & 6.261581 & $\mathrm{~S}$ & 7.962928 & 10.67169 & 10.21338 \\
\hline C & 3.867736 & 10.91582 & 5.886958 & $\mathrm{~S}$ & 7.125846 & 13.66127 & 11.12363 \\
\hline C & 3.226458 & 11.30609 & 4.702321 & $S$ & 5.12749 & 13.88891 & 8.591635 \\
\hline C & 3.798244 & 12.28644 & 3.87617 & $\mathrm{O}$ & 8.425185 & 13.21976 & 7.970739 \\
\hline C & 5.020184 & 12.87376 & 4.244503 & $\mathrm{H}$ & 3.416556 & 10.15139 & 6.527096 \\
\hline C & 5.667257 & 12.48796 & 5.426246 & $\mathrm{H}$ & 2.273721 & 10.84242 & 4.427543 \\
\hline C & 8.494337 & 9.313295 & 9.162011 & $\mathrm{H}$ & 3.296536 & 12.59051 & 2.952721 \\
\hline C & 9.143113 & 9.515392 & 7.925253 & $\mathrm{H}$ & 5.476015 & 13.63732 & 3.606135 \\
\hline C & 9.619126 & 8.421067 & 7.190653 & $\mathrm{H}$ & 6.618243 & 12.9481 & 5.708126 \\
\hline C & 9.459548 & 7.112405 & 7.676089 & $\mathrm{H}$ & 9.269431 & 10.53138 & 7.541806 \\
\hline C & 8.817903 & 6.906621 & 8.907628 & $\mathrm{H}$ & 10.12023 & 8.593291 & 6.232776 \\
\hline C & 8.338106 & 7.996896 & 9.648113 & $\mathrm{H}$ & 9.832119 & 6.260831 & 7.099117 \\
\hline C & 8.618124 & 13.34451 & 12.07623 & $\mathrm{H}$ & 8.685063 & 5.891817 & 9.295932 \\
\hline C & 9.899677 & 13.30405 & 11.48746 & $\mathrm{H}$ & 7.837616 & 7.82925 & 10.60678 \\
\hline C & 11.03953 & 13.14993 & 12.28787 & $\mathrm{H}$ & 9.997572 & 13.39108 & 10.40193 \\
\hline C & 10.92094 & 13.03677 & 13.68315 & $\mathrm{H}$ & 12.02743 & 13.12032 & 11.81734 \\
\hline C & 9.648085 & 13.07936 & 14.27356 & $\mathrm{H}$ & 11.81327 & 12.91597 & 14.30448 \\
\hline C & 8.502679 & 13.23285 & 13.47861 & $\mathrm{H}$ & 9.541915 & 12.98943 & 15.35929 \\
\hline C & 5.301595 & 15.60412 & 9.10212 & $\mathrm{H}$ & 7.513163 & 13.26412 & 13.94495 \\
\hline C & 4.161573 & 16.26372 & 9.6112 & $\mathrm{H}$ & 3.231102 & 15.70539 & 9.752964 \\
\hline C & 4.217953 & 17.62667 & 9.936709 & $\mathrm{H}$ & 3.326816 & 18.12269 & 10.33427 \\
\hline C & 5.40793 & 18.35 & 9.75893 & $\mathrm{H}$ & 5.450572 & 19.41304 & 10.01375 \\
\hline C & 6.543353 & 17.69748 & 9.250452 & $\mathrm{H}$ & 7.47575 & 18.25239 & 9.105376 \\
\hline C & 6.494495 & 16.33593 & 8.922248 & $\mathrm{H}$ & 7.381454 & 15.83386 & 8.526476 \\
\hline
\end{tabular}

